\title{
Conhecimentos, atitudes e práticas de agricultores familiares brasileiros sobre a exposição aos agrotóxicos'
}

\section{Knowledge, attitudes and practices of Brazilian family farmers on pesticide exposure}

\author{
Rafael Junqueira Burallia \\ (D) https://orcid.org/0000-0001-7006-6177 \\ E-mail: rafael.buralliøgmail.com

\section{Helena Ribeiro ${ }^{a}$} \\ (D) https://orcid.org/0000-0002-1321-7060 \\ E-mail: lenaळusp.br

\section{Renata Spolti Leãob} \\ (i) https://orcid.org/0000-0002-7047-1209 \\ E-mail: rspoltiøhotmail.com

\section{Rejane Corrêa Marquesc} \\ (D) https://orcid.org/0000-0001-6730-7769 \\ E-mail: rejanecmarquesळglobo.com

\section{Daniele Santos Silvad \\ (D) https://orcid.org/0000-0001-8021-2617 \\ E-mail: silva.danielesantosळgmail.com}

\section{Jean Remy Davée Guimarães ${ }^{d}$} \\ (D) https://orcid.org/0000-0003-2584-0009 \\ E-mail: jeanrdgळbiof.ufrj.br
}

aUniversidade de São Paulo. Faculdade de Saúde Pública. Departamento de Saúde Ambiental. São Paulo, SP, Brasil.

bUniversidade Federal de Minas Gerais. Centro de Tecnologia em Nanomateriais e Grafeno. Belo Horizonte, MG, Brasil.

'Universidade Federal do Rio de Janeiro. Campus Macaé. Macaé, RJ, Brasil.

dUniversidade Federal do Rio de Janeiro. Instituto de Biofísica Carlos Chagas Filho. Rio de Janeiro, RJ, Brasil.

\section{Correspondência}

Rafael Junqueira Buralli

Universidade de São Paulo. Faculdade de Saúde Pública. Departamento de Saúde Ambiental. Av. Dr. Arnaldo, 715, Cerqueira Cesar, São Paulo, SP, Brasil. CEP: 01246-904.

\section{Resumo}

$\mathrm{O}$ artigo discute conhecimentos, atitudes e práticas (CAP) de agricultores familiares brasileiros a respeito dos impactos na saúde e no ambiente gerados pelo uso de agrotóxicos. Trata-se de um estudo transversal misto, realizado em 2014 em São José de Ubá, RJ. A pesquisa é composta por uma etapa qualitativa, baseada em observações em campo e entrevistas com 25 participantes sobre CAP, no que se refere ao uso de agrotóxicos. A etapa quantitativa abrange avaliação sociodemográfica e de exposição aos agrotóxicos de 78 agricultores. Apesar de reconhecerem parcialmente os perigos dos agrotóxicos, os agricultores enfrentam os riscos da exposição e comumente adotam práticas laborais inadequadas. Fatores como a carência de apoio técnico e treinamento laboral, baixa escolaridade, dificuldade de compreensão das orientações de bulas e rótulos dos agrotóxicos, valor elevado e desconforto causado pelo equipamento de proteção individual (EPI), além da crença da dependência do uso de agrotóxicos, explicam parcialmente as atitudes não seguras. É preciso promover práticas agrícolas mais sustentáveis, fortalecer o apoio técnico e treinamento laboral, melhorar a comunicação e o gerenciamento dos riscos e reduzir as desigualdades de gênero entre os agricultores brasileiros, como a forma mais eficaz e imediata de prevenir os agravos relacionados ao trabalho com agrotóxicos.

Palavras-chave: Agrotóxicos; Trabalhador Rural; Agricultura Familiar; Conhecimentos, Atitudes e Práticas; Percepção de Risco.

Este estudo foi financiado pelo Conselho Nacional de Desenvolvimento Científico e Tecnológico (CNPq) pelo projeto Universal 479364/2012-5. Buralli foi financiado pela Coordenação de Aperfeiçoamento de Pessoal de Nível Superior (Capes) e Ribeiro pelo CNPq. 
This paper discusses the knowledge, attitudes, and practices (KAP) of Brazilian family farmers regarding the impact of pesticides on health and the environment. This mixed cross-sectional study was conducted in 2014 in São José de Ubá, Rio de Janeiro, encompassing two stages: one qualitative, based on field observations and interviews with 25 participants on KAP about pesticides; and one quantitative, concerning sociodemographic data and pesticide exposure assessment with 78 farmers. Despite partially recognizing the danger of pesticides, farmers face the risks of exposure and commonly adopt inappropriate work practices. Lack of technical support and occupational training, low schooling, difficulty in understanding the instructions on pesticide labels, the price and discomfort caused by protection equipment, and the belief in the need for pesticide use, partially explain the unsafe attitudes. Effective and immediate prevention of pesticide-related injuries and diseases requires promoting more sustainable agricultural practices, strengthening technical support and occupational training, improving communication and risk management of pesticides, and reducing gender inequalities among Brazilian farmers.

Keywords: Pesticides; Farmworkers; Family Farming; Knowledge, Attitudes, and Practices; Risk Perception.
No Brasil, o setor agropecuário é uma das principais bases da economia, tanto pelo agronegócio na produção de commodities para exportação, quanto pela agricultura familiar na produção de alimentos, ambos com perspectiva de crescimento. Essa expansão agropecuária tem ocorrido mediante o aumento expressivo do uso de agrotóxicos e flexibilização da legislação, tornando o país um dos maiores consumidores do mundo (Almeida et al., 2017). Entre trabalhadores agrícolas, a exposição aos agrotóxicos pode acarretar diversos efeitos agudos e crônicos à saúde, incluindo fraqueza, espasmos e tremores musculares, alterações gastrointestinais, cardiovasculares, respiratórias, neurológicas, mentais, cognitivas, endócrinas e câncer (Mostafalou; Abdollahi, 2017). No Brasil, estudos com agricultores expostos apontam efeitos respiratórios (Faria et al., 2005), mentais (Campos et al., 2016), suicídio (Faria; Fassa; Meucci, 2014) e câncer (Boccolini et al., 2014), entre outros.

Acompanhando a comercialização de agrotóxicos, as intoxicações vêm aumentando expressivamente no Brasil. Entre 2010 e 2019, foram notificadas 10.745 intoxicações por agrotóxicos relacionadas ao trabalho na agropecuária no Sistema de Informação de Agravos de Notificação (Sinan), com um coeficiente de incidência triplicando no período, de 4,o para 12,5 casos por 100.0oo trabalhadores (Brasil, 2020). Ademais, estima-se subnotificação de aproximadamente 50 casos para cada notificação de intoxicação (Carneiro et al., 2015), sendo esta possivelmente maior para o registro da relação com o trabalho e das doenças crônicas, dificilmente relacionadas aos agrotóxicos.

Especialmente em países de menor renda, onde a regulação e vigilância em saúde e ambiente são mais tolerantes ou precárias e os recursos limitados, o uso imprudente e excessivo de agrotóxicos pode aumentar a exposição e os danos à saúde (Staudacher et al., 2020). Nesses países, incluindo o Brasil, estudos realizados com agricultores apontaram diversos fatores que favorecem a exposição aos agrotóxicos, como baixa escolaridade e renda, uso de químicos altamente tóxicos, residências próximas das lavouras, pouco 
suporte técnico e treinamento para manipular substâncias perigosas, desconhecimento das rotas de exposição, uso inapropriado de equipamentos de proteção individual (EPI) e descarte inadequado de embalagens dos insumos (Manyilizu et al., 2017; Negatu et al., 2016; Pasiani et al., 2012; Petarli et al., 2019; Staudacher et al., 2020).

Contudo, as boas práticas na agricultura convencional não são plenamente efetivas para evitar a exposição aos agrotóxicos, especialmente no âmbito da agricultura familiar. Desse modo, estudos sobre conhecimentos, atitudes e práticas (CAP) tem reconhecido as práticas agroecológicas como complementares aos controles sanitário e ambiental (Petarli et al., 2019; Reus et al., 2017).

As atitudes e práticas quanto ao uso de agrotóxicos e o consequente nível de exposição humana são diretamente influenciadas pela percepção de risco e conhecimento dos agricultores. Portanto, compreender os CAP dos produtores rurais é fundamental para a elaboração e o aperfeiçoamento de políticas públicas, assim como para a proposição de alternativas mais seguras, sustentáveis e adequadas às demandas das comunidades. Nesse contexto, este artigo discute os CAP a respeito dos impactos na saúde e no ambiente gerados pelo uso de agrotóxicos, a partir dos achados de estudo de avaliação de risco. Esta pesquisa também fornece dados complementares sobre a percepção e exposição aos produtos químicos e seus possíveis efeitos à saúde.

\section{Métodos}

O estudo foi realizado em São José de Ubá (SJU), situado ao noroeste do estado do Rio de Janeiro, Brasil. Neste município, de aproximadamente 7.0oo habitantes, cerca de $56 \%$ da população vive na zona rural, apenas 16\% têm emprego formal e $40 \%$ possui renda per capita mensal de até $1 / 2$ salário mínimo, sendo o Índice de Desenvolvimento Humano Municipal (IDHM) médio - o,652 (IBGE, 2010).

A economia de SJU é baseada na agropecuária, sobretudo no cultivo de tomates. O município é um dos maiores produtores do país, com safra anual variando entre 21.00o e 32.00o toneladas entre 2007 e 2017 (IBGE, 2017). O relevo montanhoso apresenta poucas áreas de cobertura vegetal natural e processos acentuados de erosão do solo e de assoreamento dos rios e córregos, cujas águas ainda sofrem o aporte de esgoto doméstico e de agroquímicos, resultando em eutrofização e contaminação (Leão et al., 2018).

Esta pesquisa, de caráter transversal e metodologia mista, foi composta por duas etapas: (1) qualitativa, abrangendo as percepções da comunidade sobre os impactos dos agrotóxicos na saúde e no meio ambiente; e (2) quantitativa, reunindo os resultados da avaliação da exposição aos agrotóxicos e os efeitos à saúde dos agricultores em SJU. A partir dos resultados, foram integradas e discutidas as informações pertinentes aos CAP dos agricultores familiares de SJU.

A etapa qualitativa foi composta por entrevistas semiestruturadas com moradores da zona rural de SJU selecionados por conveniência não probabilística em janeiro de 2014. Foram entrevistados 25 indivíduos (E1 - E25), entre produtores agropecuários, familiares e informantes-chave. As frases mais relevantes foram transcritas por dois observadores e, ao final, revisadas e comparadas gerando registro único. Optou-se pela não gravação para que os participantes se sentissem mais confortáveis. As entrevistas ocorreram nas residências dos voluntários e o número de participantes foi determinado pelo ponto de saturação das respostas, alcançado no momento em que foi possível identificar padrões e configurar algum nível de generalização (Duarte, 2002). Este artigo descreve o perfil dos entrevistados, apresenta as principais falas e discute-as à luz da literatura científica.

A etapa quantitativa incluiu entrevistas com agricultores familiares. Elas foram baseadas em questionários sobre a exposição aos agrotóxicos durante a safra de 2014 (julho e agosto), período de maior contato com o produto. Complementarmente, observações de campo, conversas com os agricultores e registros de imagem e áudio foram usados para discutir a exposição aos agrotóxicos. Nessa etapa, foram avaliados 78 agricultores selecionados por conveniência (amostragem "bola de neve"), participantes ou não da etapa qualitativa. O tamanho amostral foi delimitado por restrições de tempo e orçamento do projeto e representou cerca de $11 \%$ dos agricultores envolvidos no plantio de tomate em SJU. 
Foram coletadas informações relativas a utilização de agrotóxicos, conhecimentos, atitudes e práticas que podem influenciar na exposição, tais como: contato atual ou pregresso, duração da exposição, idade de início do trabalho agrícola, atividades desenvolvidas, exposição doméstica (e.g. controle de pragas, hortas, contato com roupas ou equipamentos contaminados), intoxicação prévia, agrotóxicos utilizados, uso de receituário agronômico, responsável pela prescrição e dosagem dos agrotóxicos, treinamento prévio e orientações laborais, proximidade entre residências e áreas de cultivo, uso de EPI (máscara de pano ou respirador, viseira, chapéu, luvas, botas e macacão), lavagem das mãos e banho após o trabalho, consumo de alimentos e água nas áreas de cultivo, respeito ao tempo de carência, local de armazenamento dos insumos agrícolas e tratamento e destinação das embalagens utilizadas.

Neste artigo, apresentam-se as frequências absolutas e relativas para subsidiar a discussão dos conhecimentos, experiências, atitudes e práticas, enquanto maiores detalhes sobre a metodologia do estudo (Leão et al., 2018), efeitos respiratórios (Buralli et al., 2018) e sintomas mentais e de intoxicação (Buralli et al., 2020) são apresentados em estudos anteriores.

Foram incluídos apenas os indivíduos que concordaram em participar voluntariamente da pesquisa e assinaram o termo de consentimento. Este estudo foi aprovado pelo comitê de ética do Hospital Universitário Clementino Fraga Filho da Universidade Federal do Rio de Janeiro (CAAE: 30459814.5.0000.5257).

\section{Resultados}

\section{Percepções sobre os impactos do uso de agrotóxicos à saúde e ao meio ambiente}

Os produtores agropecuários, familiares e informantes-chave entrevistados em SJU $(n=25)$ responderam a respeito do uso de agrotóxicos e os possíveis efeitos à saúde humana e ao meio ambiente. Os participantes residiam na região há 33,2 $\pm 15,4$ anos, em média. O grupo voluntário foi composto por 17 homens (68\%) e 8 mulheres (32\%), com idades entre 21 e 75 anos e idade média de 56 e 51 anos, respectivamente. A maioria apresentava baixa escolaridade, contando apenas com ensino fundamental incompleto (64\%).

Aproximadamente, $70 \%$ deles trabalhavam na agropecuária com uso de agrotóxicos quando foram avaliados, entretanto, todos alegaram ter trabalhado anteriormente. A maioria dos entrevistados relatou ter aprendido a trabalhar com familiares, principalmente pais, avós, irmãos, primos e tios, enquanto apenas dois aprenderam com outros agricultores e um com técnicos especializados.

Alguns entrevistados demonstraram satisfação no trabalho agrícola, principalmente pela qualidade de vida na roça, autonomia e flexibilidade no horário de trabalho, prazer em produzir alimentos, sendo considerado por um deles como um avanço para o país.

"A hora que eu não puder mais [trabalhar] é capaz de eu entristecer”. (E16 - homem, produtor, 69 anos)

"Serviço nunca faz mal a ninguém". (E2o - homem, produtor, 6o anos)

"Se trabalhar com prevenção vejo perigo nenhum não [...] perigo tem em todo lugar”. (Eo4 - homem, produtor, 6o anos)

Entretanto, a maioria dos produtores demonstrou insatisfação com o trabalho rural, principalmente pela sobrecarga do trabalho, dificuldade de comercialização da produção, valor de venda dos produtos, exploração de atravessadores, falta de assistência técnica, dificuldade de aquisição/ empréstimo de máquinas e pelo uso de agrotóxicos. Alguns entrevistados apontaram a baixa escolaridade como um dos principais condicionantes da falta de oportunidades para além do trabalho rural.

"Não gosto do trabalho, o serviço é muito sacrificado, faço porque é preciso”. (E12 - homem, produtor, idade não declarada)

"Os atravessadores carregam direto, depois de consumido a gente vê o valor [...] diz que vai pagar 
valor, mas depois paga menos". (Eo2 - homem, produtor, 50 anos)

"Planto tomate porque não tenho estudo, não tenho esperança de que tomate dá mais dinheiro não". (Eog - homem, produtor, 55 anos)

"Não vale a pena não, trabalhar no sol e depois não vernada [...] queria que o marido arrumasse emprego na cidade, mas ele não tem estudo". (E11 - mulher, dona de casa e "ajuda" no cultivo, 51 anos)

"Emprego aqui é pouco, fábrica é pouca, pessoal fica sem escolha”. (Eo5 - mulher, auxiliar de serviços gerais, 42 anos)

A maioria dos entrevistados não reconhece - ou aceita - os riscos dos agrotóxicos ou considera-os como indispensáveis à produção agrícola, relativizando o problema da exposição, minimizando ou mesmo negando seus perigos. Parte dos agricultores assume os riscos associados ao uso dos produtos por necessidade e dependência do trabalho.

"Gostando ou não o trabalho é esse, é isso o que tenho que fazer". (Eo4 - homem, produtor, 6o anos)

"Sempre tem muita gente que trabalha na roça e passa mal, mas tem que trabalhar porque vive disso. Às vezes já tem problema e vai trabalhar na roça porque precisa". (E1o - homem, ex-produtor, 63 anos)

"Se pudesse não trabalhava [com agrotóxico] [...], mas não tem muita chance de fazer diferente". (E22 - homem, produtor, 53 anos)

"Acho que quem planta tem que usar [agrotóxico], quem não usa não tem o que colher”. (Eo4 - homem, produtor, 60 anos)

"Pra mim é normal, é meu trabalho, sei que tenho que trabalhar com veneno [...] se eu falar pra você que não faz mal eu tô mentindo". (Eo2 - homem, produtor, 50 anos)
Alguns entrevistados disseram que "o remédio [agrotóxicos] não faz mais efeito", "ficaram mais fracos" e que "parece que nem passou", enquanto outros relatam aumento na resistência das pragas e, com isso, a necessidade de usar agrotóxicos mais fortes e em maior quantidade, afirmando que "As pragas estão mais resistentes" e "se acostumou com o veneno". Três participantes consideravam que os agrotóxicos eram indispensáveis para a produção agrícola.

"Acho que tão fazendo o remédio [agrotóxico] mais fraco pra vender mais. Antigamente o remédio matava logo". (Eo2 - homem, produtor, 50 anos)

"As praga, se não for veneno brabo não mata não. Se não passar veneno muito forte não colhe nada. No início não existia nem o veneno, tudo tem que ser no veneno agora, faz mal né?". (E2o - homem, produtor, 6o anos)

Quando perguntados sobre os perigos do trabalho agrícola, 14 entrevistados (56\%) citaram os agrotóxicos e dois mencionaram os acidentes com animais (8\%) e risco de quedas (8\%). A maioria reconheceu os efeitos agudos e crônicos dos agrotóxicos à saúde humana, $24 \%$ relataram já terem se intoxicado pelo menos uma vez e $52 \%$ reportaram casos de intoxicação com familiares e conhecidos. Distintos termos foram utilizados para se referir aos químicos, como "agrotóxicos", "veneno", "pesticida”, "remédio" e "defensivos".

"O remédio [agrotóxico] faz muito mal. Isso tem que acabar, veneno brabo, tem gente que come né, tem que acabar". (E11 - mulher, dona de casa e "ajuda” no cultivo, 51 anos)

"O mais perigoso no trabalho é os remédio que irriga”. (Eo8 - homem, produtor e presidente da associação de agricultores, 42 anos)

"Todo trabalho tem seus riscos, mas a parte dos defensivos é a pior". (E21 - homem, produtor e atravessador, 48 anos) 
"Já tive problemas de saúde, fui intoxicado com o veneno". (E18 - homem, ex-produtor, 54 anos)

"Muito perigoso, muito perigoso [trabalhar com veneno], já morreu gente por causa do veneno. Já perdi colegas [...] não chegou a tomar o veneno, ele foi entrando nele. Na preparação da calda às vezes aperta a mão um pouco [usa mais agrotóxicos do que recomendado]". (E16 - homem, produtor, 69 anos)

"[O uso de agrotóxicos causa] problema no pulmão, problema de câncer, problema de tudo [...] o pessoal fica muito exposto". (Eo1 - homem, produtor, 58 anos)

"Acho que faz mal à saúde. A pessoa que trabalha muito tempo com veneno, na velhice vai ter saúde prejudicada”. (Eo4 - homem, produtor, 6o anos)

"Acho que não faz mal na hora [usar agrotóxicos], mas vai juntando e faz mal depois". (E1o - homem, ex-produtor, 63 anos)

Parte dos voluntários destacou a falta de cuidado na manipulação e pulverização de agrotóxicos, a não utilização de EPI e a carência de apoio técnico como importantes fatores de risco ao adoecimento no trabalho rural.

"Eu acho perigoso trabalhar na roça de tomate, muito veneno. A gente vê muita gente trabalhando sem proteção. As orientações são para usar camisa de manga cumprida, máscaras, calça cumprida, mas ninguém faz isso, passa o remédio de cara limpa, pega o tomate no pé e come". (E13-mulher, dona de casa que "ajudava” no cultivo, idade não declarada)

"A lavoura de tomate apresenta muitos perigos, $o$ produtor é muito desmantelado, não usa máscara, vai plantar sem camisa". (E10 - homem, ex-produtor, 63 anos)

" $E$ u acho perigoso [o trabalho do produtor], porque não tem apoio, orientação”. (E23 - mulher, professora e ex-produtora, 55 anos)

"Eu sou o químico" (Eoz - homem, produtor, 5 o anos).
Sobre o adoecimento e a relação com o trabalho rural, parte dos entrevistados afirmou não ter doenças ( $n=10 ; 40 \%)$, alguns afirmaram ter problemas de saúde, enquanto outros alegaram estar bem de saúde após terem cessado o trabalho com agrotóxicos. Os problemas de saúde mais comumente citados foram câncer, hipertensão e diabetes, respectivamente por 15 (60\%), 12 (48\%) e $10(40 \%)$ participantes, seguidos por doenças respiratórias e "viroses" ( $n=3 ; 12 \%)$, dores de cabeça e problemas ortopédicos ( $\mathrm{n}=2 ; 8 \%)$. Um informante-chave e um produtor relacionaram espontaneamente os quadros de "virose" às intoxicações por agrotóxicos.

"Depois que eu parei de plantar [a saúde] tá muito boa, antes sentia dor de cabeça, mal-estar. Um dia estava bem, outro dia estava ruim". (E18 - homem, ex-produtor, 54 anos)

"Quando não se plantava tomate não morria tanta gente de doença braba [...] 40 anos a trás a pior coisa que tinha era tuberculose, agora não é mais, tem mais câncer". (E1o - homem, ex-produtor, 63 anos)

"A saúde vareia certas coisas. Depois que começou o plantio de tomate pra cá começou a morrer gente de câncer, eu acho que veio tudo por causa dos agrotóxicos”. (E14 - homem, produtor, 74 anos)

"Muita gente já se intoxicou e nem sabe o que foi, acha que é virose". (E22 - homem, produtor e atravessador, 48 anos)

Quando perguntados sobre a saúde das crianças na região, a maioria dos participantes ( $n=20 ; 80 \%)$ relatou boa saúde e "esperteza", atribuindo à boa alimentação oferecida nas escolas, proibição do trabalho infantil e construção de creches como forma de evitar que os pais levem seus filhos para os locais de cultivo. Dentre os entrevistados supracitados, quatro (16\%) se contradisseram ao afirmar que há "bastante criança especial" e "com probleminhas de dificuldade de aprendizagem". Informação reiterada por outros três participantes, incluindo uma professora (mulher, 55 anos) que relatou muitos casos de crianças com deficiência de aprendizagem, cujas necessidades especiais são ignoradas pelos pais. 
Ao serem indagados sobre os impactos ambientais dos agrotóxicos, 10 entrevistados (40\%) relataram preocupação com a contaminação da água, do solo e ar pelo descarte inadequado das embalagens e dos resíduos de agrotóxicos. Alguns relataram que os hábitos têm melhorado e que os agricultores estão mais conscientes quanto ao manejo das embalagens usadas.

“Águas dos valões tão péssimas por conta do agrotóxico, desce pros açudes, valões. Não tem assistência para o controle de agrotóxicos na água”. (Eo7 - homem, produtor orgânico, 53 anos)

"A água é muito ruim, suja, mais tarde vai fazer mal pranossa saúde”. (E1o-homem, ex-produtor, 63 anos)

"As pessoas não tinham cuidado, jogavam água da lavagem das embalagens de agrotóxico nos valões, polui as águas”. (E18 - homem, ex-produtor, 54 anos)

"Melhorou muito, pessoas estão mais conscientes... Hoje tem recolhimento das embalagens. Raramente alguém queima, enterra ou joga em qualquer lugar".

(E25 - mulher, agente comunitária de saúde, 21 anos)

Quando questionados sobre quem deveria ser responsabilizado pelos problemas relatados, parte dos entrevistados $(n=8 ; 32 \%)$ atribuiu ao governo (sem identificar uma esfera ou gestor específico), ao próprio agricultor, ao prefeito, técnicos e secretário do meio ambiente, em menor proporção.

"O responsável é o governo [...] Lei tem até de mais, só são cumpridas pra uns, pra outros não”. (Ео3 homem, produtor, 48 anos)

"Tinha que levar um pé de chinelo [trabalhador rural] pro congresso pra falar essas coisas [os problemas da região]. Eles [os governantes] tem que preservar, não dá muito voto, mas dá vida, dá saúde”. (E16 homem, produtor, 69 anos)

"A responsabilidade é de cada produtor". (Eo8 homem, produtor/ presidente de uma associação de agricultores, 42 anos)

"Responsabilidade é do agricultor, que mexe com isso diariamente e tem que ter consciência”. (E25 - mulher, agente comunitária de saúde, 21 anos)

\section{Atitudes e práticas como fatores de risco para a exposição aos agrotóxicos}

Dentre os 78 participantes da etapa quantitativa, a idade média foi de 44.1 \pm 13.2 anos (dp) e o tempo médio de envolvimento com o trabalho agrícola foi de $27.0 \pm$ 14.3 anos. Metade dos entrevistados (50\%) começou a trabalhar ou ajudar no cultivo com menos de 12 anos de idade e outros $30 \%$ iniciaram entre 13 e 17 anos (Tabela 1).

Tabela I - Fatores de risco condicionantes da exposição aos agrotóxicos influenciados por conhecimentos, atitudes e práticas entre agricultores familiares em São José de Ubá - Rio de Janeiro, Brasil, $2014 \quad(n=78)$

\section{Variáveis de interesse}

Idade (média em anos $\pm d p$ ) a

Anos de trabalho rural (média em anos $\pm d p$ ) a

Idade em que começou a trabalhar no cultivo

$\leq 12$ anos

Entre $13-17$ anos

$\geq 18$ anos

Sexo

Masculino

Feminino

\section{Total}

$\%$

$$
\begin{aligned}
& 44,1 \pm 13,2 \\
& 27,0 \pm 14,3
\end{aligned}
$$

50,0

39

29,5

20,5

57,7

45

42,3

33 


\section{Tabela I-Continuação}

\section{Variáveis de interesse}

\section{Total}

Estado civil

Solteiro ou divorciado

Casado ou amasiado

Renda familiar mensal ${ }^{b}$

Até dois salários mínimos

Mais de dois salários mínimos

Escolaridade (em anos de estudo; IIQ) ${ }^{c}$

Possui exposição domiciliar (se sim)

Distância da residência a locais de plantio

$$
\text { Até } \mathrm{Ikm}
$$

Mais de $1 \mathrm{~km}$

Recebeu treinamento laboral ou apoio técnico

Uso de equipamentos de proteção individual - EPI (se sim)

Algum EPI
Botas
Luvas
Máscara
Avental
Chapéu
Viseira
Consome água e alimentos na lavoura
Lava as mãos após trabalhar na lavoura
Toma banho após trabalhar na lavoura
Intoxicação prévia (se sim)
Dados com distribuição normal, apresentados em média e desvio padrão (dp);
istribuição anormal, apresentados em mediana e intervalo interquartil (IIQ 25-75
A maioria dos participantes era casada, possuía
aixa escolaridade e renda familiar, morava até
km de distância de áreas de cultivo, nunca recebeu
uporte técnico ou treinamento e estava exposta
omesticamente aos agrotóxicos, seja utilizando-os
ara controle de pragas nas residências e entorno,
através do contato com roupas e equipamentos
juntamente com as demais roupas da família.

$\%$

14,1

85,9 II 67 $71,8 \quad 56$

28,2 22 4,$0 ; 3,0-8,0$

87,2

$84,6 \quad 66$

15,4

14,1 II

67,9

$53,8 \quad 42$

52,6

$50,0 \quad 39$

$39,7 \quad 31$

37,2

14,1 II

$91,0 \quad 71$

$80,8 \quad 63$

$\begin{array}{ll}60,3 & 47\end{array}$

17,9

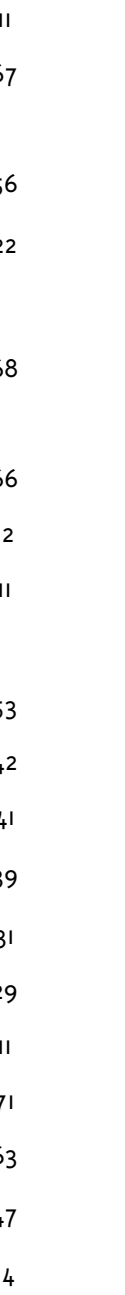

4 ; ${ }^{\mathrm{c}}$ Dados com \%).

Cerca de $58 \%$ dos entrevistados eram homens que se dedicavam majoritariamente às atividades de manipulação e aplicação de agrotóxicos, enquanto as mulheres ( $42 \%)$ normalmente desempenhavam outras atividades, como semeadura, adubação, colheita, além de "puxarem a mangueira" durante a irrigação e pulverização de agrotóxicos. Os entrevistados afirmaram utilizar 49 agrotóxicos de 31 grupos químicos distintos, sendo a maioria classificada como extremamente e altamente tóxica e alguns proibidos no cultivo de tomates no Brasil. 
Esses agroquímicos eram pulverizados em misturas formuladas com múltiplos agrotóxicos entre 1-3 vezes $(85,7 \%)$ ou $4-7$ vezes $(11,9 \%)$ por semana durante o período da safra.

Aproximadamente $68 \%$ dos participantes afirmaram utilizar algum tipo de EPI, sendo botas, luvas e máscara os mais utilizados, enquanto a viseira foi o EPI menos citado (Tabela 1). Porém, durante as visitas de campo, foi observado que os trabalhadores utilizavam máscaras de tecido, e não o respirador recomendado. Além disso, nenhum trabalhador foi visto utilizando EPI completo. Alguns entrevistados disseram não utilizar EPI porque os consideravam "caros", "quentes" e "desconfortáveis". Sobre outras atitudes e práticas que podem aumentar a exposição aos agrotóxicos, 91\% dos agricultores afirmaram consumir água e alimentos nos locais de cultivo, inclusive nos dias em que aplicam agrotóxicos. Respectivamente, cerca de $80 \%$ e $60 \%$ deles afirmaram lavar as mãos e tomar banho após trabalhar no cultivo (Tabela 1), embora essas práticas sejam mais comuns após o dia de trabalho e não entre as atividades do cultivo.

Alguns participantes do estudo não responderam determinadas questões por decisão pessoal, por desconhecimento da resposta ou por não realizarem a atividade apontada. Sobre a utilização de receituário agronômico, 48\% dos respondentes disseram nunca utilizar ou não saber como utilizar. Quando questionados se liam (ou pediam para alguém ler) os rótulos e instruções dos agrotóxicos, $44 \%$ afirmaram ler frequentemente, $42 \%$ relataram nunca ler e $14 \%$ disseram ler às vezes, geralmente quando se tratava de produto novo.

Sobre quem recomendava os agrotóxicos que deveriam ser utilizados, 30 agricultores (39\%) afirmaram ser os vendedores ou agrônomos, 15 (19\%) disseram ser eles próprios, outros produtores ou os proprietários das lavouras e oito entrevistados (10\%) disseram não saber. Cerca de 30\% dos aplicadores não sabiam quais agrotóxicos utilizavam, em virtude de pulverizarem a mistura preparada por terceiros (Buralli et al., 2020). Sobre quem orientava as doses e frequência de aplicação, dos respondentes dessa pergunta ( $n=58), 29$ entrevistados (50\%) citaram os vendedores e agrônomos, 15 (26\%) disseram ser eles próprios, outros produtores ou os proprietários e 14 (24\%) afirmaram seguir o recomendado nas bulas e rótulos dos produtos. Ao serem questionados a respeito do período de carência entre a última aplicação do agrotóxico e a colheita, entre aqueles que responderam ao questionamento, apenas cinco (11\%) alegaram sempre respeitar, enquanto $22(50 \%)$ afirmaram obedecer frequentemente e 17 (39\%), ocasionalmente.

Cerca de $58 \%$ dos agricultores afirmaram armazenar agrotóxicos em áreas específicas para insumos nos locais de cultivo, 37\% em local reservado, externo à residência e 5\% dentro dos próprios domicílios. Quando perguntados sobre o local de descarte das embalagens usadas de agrotóxicos, 56\% afirmaram entregar ou aguardar o recolhimento pela prefeitura para disposição em galpão municipal (construído em 2013), enquanto o restante declarou devolver aos pontos de compra. Sobre os procedimentos adotados com as embalagens anteriormente ao descarte, $42 \%$ disseram lavar e guardar em sacos plásticos, $28 \%$ afirmaram guardar em sacos ou em ambiente reservado até o descarte e $19 \%$ assumiram lavar, furar e guardar em sacos plásticos. Apenas 11\% alegaram realizar a tríplice lavagem, furar as embalagens e armazenar em ambientes adequados até o descarte.

Muitos sintomas compatíveis com intoxicação por agrotóxicos foram autorreferidos (Buralli et al., 2020), apesar de apenas $18 \%$ dos entrevistados afirmarem ter se intoxicado durante o trabalho rural (Tabela 1).

\section{Discussão}

A maioria dos agricultores familiares avaliados em SJU reconheceu a exposição aos agrotóxicos como um risco à saúde, corroborando outros estudos com agricultores brasileiros (Gregolis; Pinto; Peres, 2012; Pasiani et al., 2012; Petarli et al., 2019). Apesar disso, muitos consideraram o contato como inevitável e inerente ao trabalho agrícola, em uma atitude de minimização e de negação do risco. A auto imputação quanto aos danos ambientais e à saúde pelo uso dos agrotóxicos foi claramente identificada nos relatos dos participantes e nenhum deles relacionou a problemática com o sistema de agricultura convencional. Os participantes deste estudo vivem em cenário de elevada vulnerabilidade socioambiental e apresentaram diversos efeitos à saúde respiratória, 
incluindo sintomas e alterações da função pulmonar (Buralli et al., 2018), sintomas mentais e de intoxicação (Buralli et al., 2020) associados ao contato com os produtos. Os conhecimentos dos agricultores sobre os efeitos dos agrotóxicos na saúde e no meio ambiente não necessariamente influenciam suas atitudes e práticas e não garantem a prevenção da exposição e dos efeitos deletérios. O contato com agrotóxicos, especialmente nas dinâmicas de trabalho estudadas, compromete a saúde e qualidade de vida dos agricultores e seus familiares, a força de trabalho na agropecuária, a produção de alimentos e gera danos individuais e coletivos, com enormes custos sociais e econômicos às famílias, ao sistema de saúde e à previdência social (Brasil, 2020).

No Brasil, outros estudos com agricultores familiares indicam alguns aspectos em comum, como a baixa escolaridade e renda, condições precárias de saneamento, exposição a múltiplos agrotóxicos altamente tóxicos, pouco ou nenhum suporte técnico e treinamento (Carneiro et al., 2015; Pedlowski et al., 2012; Petarli et al., 2019). Cerca de $15 \%$ dos trabalhadores agropecuários brasileiros nunca frequentaram a escola, $24 \%$ têm apenas ensino primário e 19\% fundamental (IBGE, 2017). A escolaridade é fator determinante da renda e de adesão às medidas de segurança e prevenção da saúde (Brasil, 2020). A baixa escolaridade pode dificultar a leitura e compreensão das orientações de segurança sobre o uso dos agrotóxicos. Ademais, as informações de bulas e rótulos são ambíguas e de difícil compreensão, algumas impraticáveis no contexto da agricultura familiar (Pedlowski et al., 2012; Waichman; Eve; Nina, 2007).

Em outro estudo, agricultores reclamaram que as fontes eram pequenas, as instruções longas e a linguagem muito técnica. Nenhum participante acertou a toxicidade dos agrotóxicos pelas cores dos rótulos e poucos entenderam as imagens informativas (Waichman; Eve; Nina, 2007). Isso reforça a importância de melhorar a comunicação de risco sobre agrotóxicos entre agricultores brasileiros e fornecer treinamento para utilização desses químicos. Em SJU, a maioria dos participantes possuía baixa escolaridade, tinha pouco ou nenhum suporte técnico e treinamento em segurança laboral e desconhecia os agrotóxicos que utilizava, limitando a percepção do risco e a adoção de medidas protetivas.
Alguns hábitos, atitudes e práticas observados em SJU são especialmente preocupantes e podem aumentar a exposição ocupacional e ambiental aos agrotóxicos, tais como: uso de misturas de múltiplos agrotóxicos de elevada toxicidade, exposição frequente e repetida, uso domiciliar e peridomiciliar, a não utilização de EPI ou utilização incompleta, consumo de alimento e bebida nos locais de cultivo, banhos apenas ao final da jornada de trabalho, a não utilização de receituários agronômicos, a desobediência ao tempo de carência recomendado, armazenamento dos produtos em local inadequado e residências próximas às áreas de cultivo. Essas atitudes também já foram observadas em outros estudos com agricultores brasileiros (Carneiro et al., 2015; Gregolis; Pinto; Peres, 2012; Pasiani et al., 2012; Pedlowski et al., 2012; Petarli et al., 2019) e de distintos países de menor renda (Manyilizu et al., 2017; Negatu et al., 2016; Staudacher et al., 2020). Na Costa Rica e Uganda, por exemplo, apesar da maioria dos agrotóxicos utilizados ser altamente tóxica e 90\% dos agricultores estarem cientes dos efeitos na saúde, apenas $11 \%$ e $2 \%$ deles, nos respectivos países, utilizavam EPI ao manipular agrotóxicos (Staudacher et al., 2020).

O trabalho rural no Brasil, especialmente nas pequenas e médias propriedades, é ensinado de pais para filhos desde tenra idade, determinando a organização das famílias em torno da atividade agropecuária e expondo todos integrantes do núcleo familiar aos riscos elevados do contato com os agrotóxicos (Gregolis; Pinto; Peres, 2012; Reis et al., 2017). Em SJU, enquanto os homens manipulam e pulverizam agrotóxicos, as mulheres realizam atividades agrícolas consideradas de "menor exposição", muitas vezes conduzidas, concomitantemente ou no mesmo dia, à aplicação de agrotóxicos, como puxar a mangueira para pulverização, amarrar os brotos, colher os frutos, entre outras. Adicionalmente, são responsáveis pela lavagem das roupas e equipamentos utilizados. Acompanhando o enredo, a maioria das agricultoras avaliadas em SJU não utilizava EPI, possuía menos treinamento em comparação aos agricultores do sexo masculino e reportou mais sintomas autorreferidos sugestivos de intoxicação aguda e crônica aos agrotóxicos (Buralli et al., 2018, 2020). 
Em comparação aos homens, as mulheres deste estudo demonstraram maior preocupação com o potencial de efeitos negativos dos agrotóxicos à saúde, contudo, tal percepção não se traduziu em maiores ações de proteção, dadas as condicionantes culturais da produção na tratativa dos gêneros. As agricultoras familiares são fundamentais na organização e execução do trabalho agrícola e, consequentemente, estão mais expostas aos agrotóxicos. Elas se tornam mais vulneráveis por também se encarregarem de tarefas domésticas que incluem a aplicação de agrotóxicos no domicílio e peridomicílio e a lavagem de roupas e acessórios utilizados no campo. As agricultoras também transitam mais frequentemente entre os locais de plantio e residência e estabelecem contato com um número maior de trabalhadores (London et al., 2002). Portanto, políticas públicas voltadas às mulheres agricultoras poderiam contribuir para uma produção mais segura, reverberando na proteção das famílias envolvidas na agropecuária.

De maneira geral, é fundamental melhorar o apoio técnico e a capacitação dos agricultores familiares brasileiros sobre as medidas de proteção aos perigos do trabalho agrícola, especialmente relativos ao uso de agrotóxicos, como forma mais eficaz e imediata de prevenir os agravos relacionados ao trabalho com substâncias químicas. Para isso, deve-se fortalecer as ações interinstitucionais de vigilância e assistência em saúde com foco nas populações agropecuárias, a exemplo da Política Nacional de Saúde Integral das Populações do Campo, Floresta e Águas (PNSIPCF) e Vigilância em Saúde de Populações Expostas a Agrotóxicos (VSPEA).

Modelos de produção mais sustentáveis e adequados à agricultura familiar também devem ser apoiados e estimulados para a redução dos passivos ambientais e sociais, especialmente em cenário de franca expansão da produção agrícola e do uso de agrotóxicos. Um estudo constatou fortes semelhanças entre as tendências de aumento da produtividade de commodities agrícolas e das intoxicações por agrotóxicos, sobretudo, a partir dos anos de 1990 (Porto; Soares, 2012). A pesquisa ressalta que os riscos de intoxicação aguda seriam ainda maiores em pequenas propriedades, uma vez que os fatores de risco, tais como o uso de pulverizador costal, a não utilização de receituário agronômico e de EPI e a ausência de assistência técnica, entre outros, estão mais presentes. A alegação dos agricultores de SJU de que os agrotóxicos "ficaram mais fracos" e "parece que nem passou” também representa um importante fator de risco, considerando a necessidade de utilização de mais produtos e em maior quantidade.

No Brasil, a notificação das doenças relacionadas aos agrotóxicos é subestimada e são escassas as avaliações de contato e efeitos na saúde de agricultores familiares, dificultando a quantificação precisa dos efeitos agudos e crônicos decorrentes dos complexos cenários de exposição. Em SJU, por exemplo, inexistem mecanismos de vigilância em saúde com profissionais capacitados para a identificação e notificação de intoxicações. Portanto, também é urgente aprimorar o registro de doenças relacionadas ao trabalho com esses produtos químicos e promover estudos epidemiológicos que elucidem os cenários de exposição e efeitos na saúde dos agricultores, principalmente com acompanhamento longitudinal e biomarcadores sensíveis, avaliando agravos agudos e crônicos, efeitos de misturas de múltiplos agrotóxicos, entre outros.

\section{Considerações finais}

Apesar de reconhecerem parcialmente os riscos da exposição aos agrotóxicos, os agricultores comumente adotam práticas laborais inadequadas, favorecendo consideravelmente seu contato com os produtos químicos. A crença de que o uso de agrotóxicos é inerente à produção agrícola e a condição de elevada vulnerabilidade socioambiental contribuem para atitudes de minimização dos riscos e para resistência em aderir às práticas de produção mais sustentáveis.

Para prevenir riscos, promover a saúde, o bem-estar e a sustentabilidade na agricultura familiar, é primordial o acesso à educação de qualidade nas áreas rurais, a assistência técnica e o treinamento ocupacional dos agricultores brasileiros, transformando conhecimentos, atitudes e práticas acerca dos impactos dos agrotóxicos na saúde e no ambiente. Para isso, deve-se fortalecer as ações de vigilância, promoção e assistência em saúde, bem como as políticas e os programas específicos para essas populações. 
A doação ou subsídios para aquisição de EPI e o desenho de modelos que proporcionem maior conforto ergonômico e térmico poderiam aumentar a adesão dos trabalhadores às boas práticas e reduzir a exposição humana. Também é preciso admitir a iniquidade de gênero que deriva da tradicional organização do trabalho agrícola e predispõe as mulheres a um maior risco de exposição aos agrotóxicos. O reconhecimento de que a “ajuda” das mulheres na produção agrícola é trabalho pode se traduzir em maior segurança sanitária e proteção para a própria agricultura familiar.

Por fim, cabe ressaltar que a promoção de práticas agrícolas mais sustentáveis e a restrição do uso de agrotóxicos (especialmente os mais tóxicos) são as maneiras mais efetivas de reduzir a exposição. Portanto, políticas públicas e de crédito nesse preceito são muito necessárias.

\section{Referências}

ALMEIDA, M. D., CAVENDISH, T. A., BUENO, P. C. et al. A flexibilização da legislação brasileira de agrotóxicos e os riscos à saúde humana: análise do Projeto de Lei ${ }^{0}$ 3.200/2015. Cadernos de Saude Pública, Rio de Janeiro, v. 33, n. 7, p. 1-11, 2017. DOI: 10.1590/0102-311X00181016

BOCCOLINI, P. M. M., ASMUS, C. I. R. F., CHRISMAN, J. R. et al. Stomach cancer mortality among agricultural workers: results from a death certificate-based case-control study. Cadernos de Saúde Coletiva, Rio de Janeiro, v. 22, n. 1, p. 86-92, 2014. DOI: 10.1590/1414$462 \mathrm{X} 201400010013$

BRASIL. Ministério da Saúde. Perfil sociodemográfico e epidemiológico dos trabalhadores agropecuários do Brasil, 2010 a 2019. Boletim Epidemiológico, Brasília, DF, v. 51, n 39, 2020. Disponível em: <https://www.gov. $\mathrm{br} / \mathrm{saude} / \mathrm{pt}-\mathrm{br} / \mathrm{media} / \mathrm{pdf} / 2020 /$ outubro/23/ boletim_epidemiologico_svs_39.pdf $>$. Acesso em: 8 jul. 2021.

BURALLI, R. J., RIBEIRO, H., MAUAD, T. et al. Respiratory condition of family farmers exposed to pesticides in the state of Rio de Janeiro, Brazil. International Journal of Environmental Research and Public Health, Rockville, v. 15, n. 1203, p. 1-14, 2018. DOI: 10.3390/ijerph15061203

BURALLI, R. J., RIBEIRO, H., IGLESIAS, V. et al. Occupational exposure to pesticides and health symptoms among family farmers in Brazil. Revista de Saúde Pública, São Paulo, v. 54, n. 133, p. 1-12, 2020. DOI: 10.116o6/s15188787.2020054002263

CAMPOS, Y., SILVA, V. S. P., MELLO, M. S. C. et al. Exposure to pesticides and mental disorders in a rural population in Southern Brazil.

Neurotoxicology, Rockville, v. 56, p. 7-16, 2016. DOI: 10.1016/j.neuro.2016.06.002

CARNEIRO, F. F., AUGUSTO, L. G. S., RIGOTTO, R. M. et al. (Org.). Dossiê ABRASCO: um alerta sobre os impactos dos agrotóxicos na saúde. São Paulo: Expressão Popular, 2015.

DUARTE, R. Pesquisa qualitativa: reflexões sobre o trabalho de campo. Cadernos de Pesquisa, São Paulo, n. 115, p. 139-154, 2002. DOI: 10.1590/So10o15742002000100005

FARIA, N. M. X., FACCHINI, L. A., FASSA, A. G. et al. Pesticides and respiratory symptoms among farmers. Revista de Saúde Pública, São Paulo, v. 39, n. 6, p. 973-981, 2005. DOI: 10.1590/Soo3489102005000600016

FARIA, N. M. X.; FASSA, A. G.; MEUCCI, R. D. Association between pesticide exposure and suicide rates in Brazil. Neurotoxicology, Amsterdam, v. 45, p. 355-362, 2014. DOI: 10.1016/j. neuro.2014.05.003

GREGOLIS, T. B. L.; PINTO, W. J.; PERES, F. Percepção de riscos do uso de agrotóxicos por trabalhadores da agricultura familiar do município de Rio Branco, AC. Revista Brasileira de Saúde Ocupacional, São Paulo, v. 37, n. 125, p. 99-113, 2012. DOI: 10.1590/So30376572012000100013

IBGE - INSTITUTO BRASILEIRO DE GEOGRAFIA E ESTATÍSTICA. Censo Demográfico. 2010. Disponível em: <https://cidades.ibge.gov.br/ brasil/rj/sao-jose-de-uba/panorama>. Acesso em: 15 mar. 2019. 
IBGE - INSTITUTO BRASILEIRO DE GEOGRAFIA E ESTATÍSTICA. Censo Agropecuário. 2017.

Disponível em: <https://censos.ibge.gov.br/ agro/2017/>. Acesso em: 6 abr. 2020.

LEÃO, R. S., MARQUES, R. C., BURALLI, R. J. et al. Avaliação de saúde pública por exposição a agroquímicos: uma experiência com a agricultura familiar no noroeste do Rio de Janeiro. Sustentabilidade em Debate, Brasília, DF, v. 9, n. 1, p. 81-94, 2018. DOI: 10.18472/SustDeb. vgn1.2018.26956

LONDON, L., WESSELING, C., KISTING, S. K. Pesticide usage and health consequences for women in Developing Countries: Out of sight, out of mind? International Journal Occupational Environmental Health, London, v. 8, n. 1, p. 46-59, 2002. DOI: 10.1179/oeh.2002.8.1.46

MANYILIZU, W. B., MDEGELA, R. H., HELLEVE, A. et al. Self-Reported Symptoms and Pesticide Use among Farm Workers in Arusha, Northern Tanzania: A Cross Sectional Study. Toxics, Rockville, v. 5, n. 4, p. 1-13, 2017. DOI: 10.339o/ toxics5040024

MOSTAFALOU, S.; ABDOLLAHI, M. Pesticides: an update of human exposure and toxicity. Archives of Toxicology, Rockville, v. 91, n. 2, p. 549-599, 2017. DOI: 10.1007/soo204-016-1849-X

NEGATU, B., KROMHOUT, H., MEKONNEN, Y. et al. Use of chemical pesticides in Ethiopia: A cross-sectional comparative study Onknowledge, attitude and practice of farmers and farm workers in three farming systems. Annals of Occupational Hygiene, Rockville, v. 6o, n. 5, p. 551-566, 2016. DOI: 10.1093/annhyg/mewoo4

PASIANI, J. O., TORRES, P., SILVA, J. R. et al. Knowledge, attitudes, practices and biomonitoring of farmers and residents exposed to pesticides in Brazil. International Journal of Environmental Research and Public Health, Rockville, v. 9, n. 9, p. 3051-3068, 2012. DOI: 10.3390/ijerph9093051

PEDLOWSKI, M. A., CANELA, M. C., TERRA, M. A. C. et al. Modes of pesticides utilization by Brazilian smallholders and their implications for human health and the environment. Crop Protection, Amsterdam, v. 31, n. 1, p. 113-118, 2012. DOI: 10.1016/j.cropro.2011.10.002

PETARLI, G. B., CATTAFESTA, M., LUZ, T. C. et al. Exposição ocupacional a agrotóxicos, riscos e práticas de segurança na agricultura familiar em município do estado do Espírito Santo, Brasil. Revista Brasileira de Saúde Ocupacional, São Paulo, v. 44, p. 1-13, 2019. DOI: 10.1590/23176369000030418

PORTO, M. F.; SOARES, W. L. Modelo de desenvolvimento, agrotóxicos e saúde: um panorama da realidade agrícola brasileira e propostas para uma agenda de pesquisa inovadora. Revista brasileira de saúde ocupacional, São Paulo, v. 37, n. 125, p. 17-31, 2012.

REIS, M. M., OLIVEIRA, A. P. N., TURCI, S. R. B. et al. Conhecimentos, atitudes e práticas de agricultoras sobre o processo de produção de tabaco em um município da Região Sul do Brasil. Cadernos de Saúde Pública, Rio de Janeiro, v. 33, p. 148-161, 2017. DOI: 10.1590/o102-311Xooo80516

STAUDACHER, P., FUHRIMANN, S., FARNHAM, A. et al. Comparative Analysis of Pesticide Use Determinants Among Smallholder Farmers From Costa Rica and Uganda. Environmental Health Insights, Rockville, v. 14, p. 1-15, 2020. DOI: 10.1177/1178630220972417

WAICHMAN, A. V.; EVE, E.; NINA, N. C. S. Do farmers understand the information displayed on pesticide product labels? A key question to reduce pesticides exposure and risk of poisoning in the Brazilian Amazon. Crop Protection, Amsterdam, v. 26, n. 4, p. 576-583, 2007. DOI: 10.1016/j.cropro.2006.05.011

\section{Contribuição dos autores}

Buralli, Leão, Marques, Guimarães foram responsáveis pela concepção e planejamento do estudo. Buralli, Ribeiro, Leão, Marques, Guimarães elaboraram e revisaram o manuscrito. Todos coletaram, analisaram e interpretaram os dados $e$ realizaram a revisão crítica e aprovação da versão final.

Recebido: 02/06/2021

Reapresentado: 02/06/2021

Aprovado: 06/07/2021 